\section{An investigation of complete denture teaching in the UK: part 1. A survey of undergraduate teaching}

\author{
M. Wieder, ${ }_{1}^{1}$ M. Faigenblum, ${ }^{2}$ A. Eder ${ }^{2}$ and C. Louca ${ }^{* 2}$
}

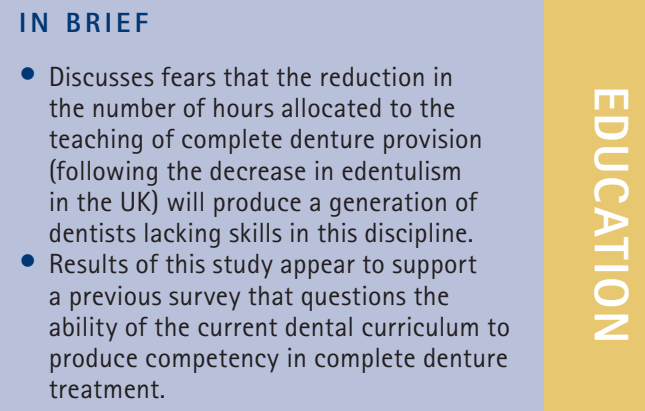


their respective websites for information specifically related to complete dentures.

Email messages outlining the purpose of the investigation were sent to the relevant heads of department. The communication contained a questionnaire and a request that it should be passed to the most appropriate member of staff for completion.

The questionnaire consisted of four closed questions on the dental curriculum requiring numerically based responses and one open question:

1. How many lecture hours are devoted to complete dentures?

2. How much clinical time is devoted to complete dentures?

3. How much laboratory time is devoted to complete dentures?

4. How many complete denture cases is an undergraduate expected to finish before qualification?

5. I would appreciate your comments regarding the present position of complete denture undergraduate education.

The dental schools responding to the questionnaire were assigned a number and the letter N (north) or S (south) depending on where they were located relative to an arbitrary line across the Midlands in England.

\section{RESULTS}

Thirteen schools responded but the replies were not uniform, as some respondents appeared unwilling or unable to give definitive figures due to the structure of their particular programme. Most schools required follow-up emails to encourage replies. This apparent reluctance could be explained by the fact that the same schools had only recently been comprehensively surveyed on the same subject. ${ }^{9}$

The results indicated that there was a great disparity between schools in the overall number of hours devoted to teaching the subject (Fig. 1).

\section{LABORATORY/CLINICAL/ LECTURE HOURS}

The number of lecture hours spent on complete dentures was relatively uniform. One school (10) recorded 42 hours while schools 6 and 8 spent 28 hours. The remainder varied between six to 15 hours.

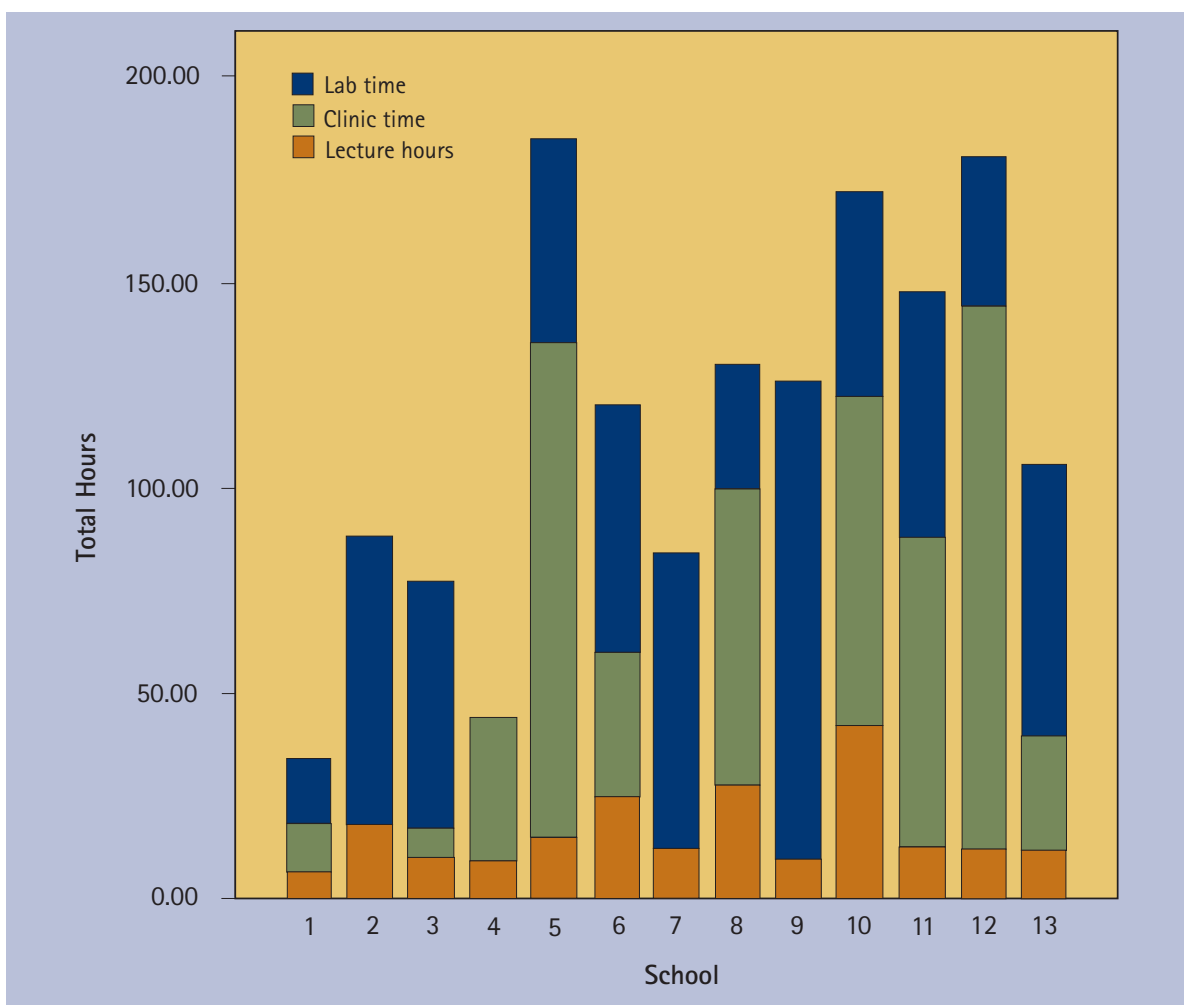

Fig. 1 Time apportioned between the laboratory, clinic and the lectures

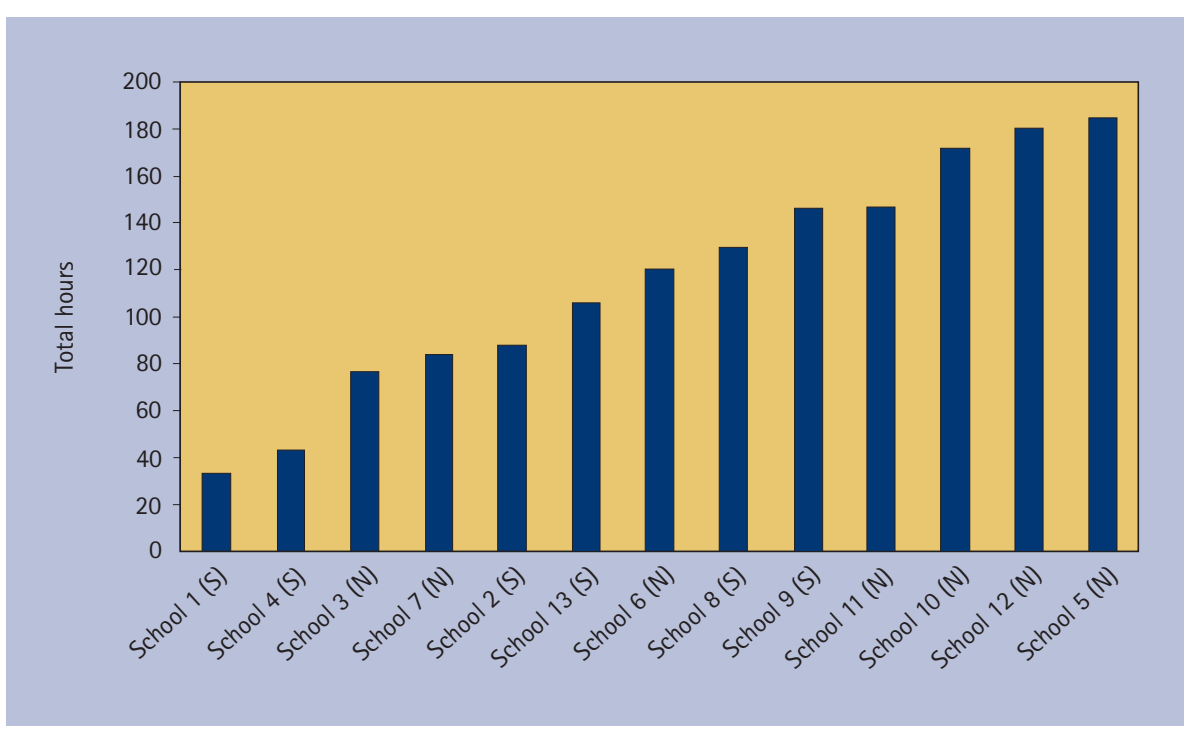

Fig. 2 Dental schools labelled north $(\mathrm{N})$ and south $(\mathrm{S})$ in ascending order of total hours devoted to complete dentures

Schools 2, 3, 9, 13 devoted more time to laboratory work than clinical work, whereas schools 5, 12, 8 devoted more time to clinical work. School 2 stated that they did not devote any clinic time solely to complete dentures. School 4 could not confirm any dedicated clinical time but they reported that aspects of complete dentures are included in dental 'technology' laboratory teaching. Schools 7 and 9 could not give an exact figure for clinic time. The former stated that it was 'impossible to say'; the latter reported 'as much as necessary'.
Although it is evident from the actual responses that some schools had difficulty in answering the question in terms of a figure for actual hours, the general emphasis adopted in the schools could be gauged even if the actual hours plotted on the histograms do not tell the complete story. Overall it can be seen that there is no uniform approach to the teaching of the subject (Fig. 1).

\section{REGIONAL VARIATION}

According to the Adult Dental Health Surveys a higher percentage of the Scottish 


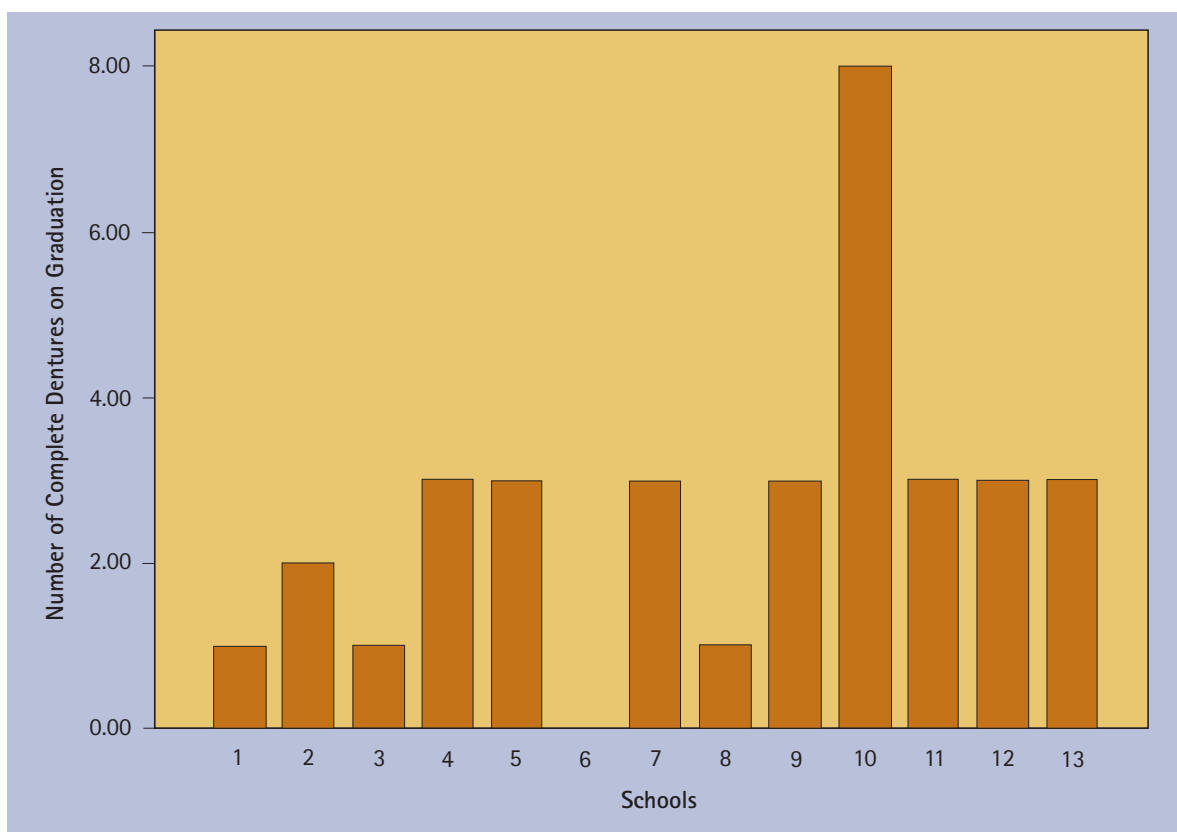

Fig. 3 Comparing the number of complete dentures expected to be completed by students by the time of qualification

and Welsh populations are edentulous and there are regional variations in England itself, 4,5 which may reflect the socio-economic differences in the regions, which is a factor brought out in the last survey of 2009.

After the dental schools were assigned a north(N)/south(S) region they were then arranged according to increasing number of total hours devoted to complete dentures (Fig. 2).

The results may indicate a possible north/south divide with the schools devoting the least time to the subject (schools $1,2,4)$, representing the southern region of the UK. This possible north/south divide is further suggested by the comments that are discussed below. The notable exception is school 3, a northern school, which is among the low values. However, from the comments (see below), it is apparent that there had been a positive decision to cut the complete denture curriculum in that school.

\section{COMPLETE DENTURE QUOTAS}

The minimum number of complete dentures expected to be produced by the undergraduate students on qualification is shown in Figure 3, although some responses were a range of values. School 7 reported that the minimum requirement would be exceeded by most students as opposed to school 3 which admitted that it is rare for students to do more than the minimum of one complete denture.
Generally, the students are expected to have completed between one and three complete dentures during their studies, with most schools expecting three complete dentures to have been made. The obvious exceptions are school 10, where eight complete dentures are expected and school 6 where there is no quota for complete dentures although they devote over 120 hours to the teaching of the subject and expect competency to be achieved in years 2-5. School 1 devoted the least time to the subject and expected the least number of dentures to be produced that is, one.

With the exception of school 10, which for regional demographics has no shortage of patients for its students (see details below), all the other schools seem to have low expectations for their students to be practically trained and experienced in the production of complete dentures.

\section{COMMENTS}

The comments section allowed the respondents to provide an opinion about their own school's approach to the teaching of the subject and any thoughts that they might have about the future direction of their teaching. These comments were categorised, using qualitative data analysis, ${ }^{11}$ and coded.

\section{(i) Regional variation}

The Adult Dental Health Surveys, ${ }^{4,5}$ while confirming the decline in the edentulous population as a percentage of the total, also highlighted the fact that there is a regional variation in the UK with a higher percentage of edentulous individuals in the northern regions. This is borne out in our study and may be contributing to the disparity in the teaching of the dental schools and in the experience and competence of the undergraduates.

Comments from the participating schools confirm this:

Dental school 12 (north): 'In this geographical area there are still significant numbers of edentulous patients who require care and therefore training in complete dentures is an important part of undergraduate education.'

Dental school 13 (north): 'We have absolutely no shortage of complete denture cases in this part of the world.'

In contrast a southern dental school commented:

Dental school 1 (south): 'We are finding it increasingly more difficult to recruit enough $\mathrm{C} / \mathrm{C}$ patients for students to have the opportunity to treat more than one $C / C$. In reality our current $3 \mathrm{rd}$ and 4 th year students will be lucky if they get the opportunity to treat one C/C from beginning to end before they graduate in the 5th year.'

This regional variation manifests itself in the clinical experience of the undergraduate. The number of complete dentures expected to be made is extremely low, one to three, in most schools with an exception of eight reported at a northern school.

\section{(ii) Competence}

As a consequence of the reduced curriculum and lack of patient experience some schools were worried about the competence of the newly qualified dentist to produce complete dentures.

Dental school 13 (north): 'Sadly, not enough time is being devoted to the topic. And it has nothing to do with the statistics in the last Adult Dental Health Survey. We have absolutely no shortage of complete denture cases in this part of the world.'

Dental school 11 (north): 'Within the time devoted to UG complete dentures we are unable to produce a student who is competent upon graduation at delivering this patient care. There is a lack of clinical/academic expertise, in the number of personnel, to allow a good quality teaching/learning experience and quality clinical 
care. The need for and value of complete denture skills is ill appreciated by those designing dental school curricula.'

Dental school 3 (north): 'The undergraduate teaching of complete denture teaching has been cut dramatically and continues to be cut. This year we have lost further laboratory teaching, so the students no longer complete clinical work for a patient. Ten years ago students would complete treatment for 5-6 complete denture patients. They would produce the technical work for one case. Now we are down to 1-2 clinical cases, with all technical work produced by technicians. Students here gain an experience of complete denture prosthetics but it would be hard to say that the majority are competent in this subject when they qualify.'

Other schools are more sanguine:

Dental school 6 (north) did not register a quota for the making of complete dentures: 'Sufficient to enable the graduate to be a safe beginner.'

Dental school 4 (south): 'I feel that the time devoted is reasonably appropriate.'

\section{(iii) Curriculum constraints}

Some schools understand the importance of the subject in the curriculum but are not able to fulfil this in practice for various reasons.

Dental school 10 (north): 'Perforce it is constrained owing to: $a$. Reduced percentage clinical time, $b$. Complexity of cases many are unsuitable for undergraduate.'

Dental school 7 (north): 'All wet fingered dentists know that you need to be able to make a complete denture yourself as a student to understand what is going on. The concept of replacing time in the prosthetics laboratory with video demonstrations is wrong.'

Dental school 5 (north): 'I think it is essential that it remains in the UG curriculum and that it starts to encompass implant supported overdentures.'

\section{(iv) Integration into restorative dental curriculum}

Some schools are integrating complete denture prosthetics into the general prosthodontics course and therefore reducing the importance of complete dentures as a unique subject.

Dental school 2 (south): 'Fixed removable and implant prosthetics form a continuum rather than being discrete but parts are aimed at complete dentures to a greater or lesser extent. I do not believe that it is appropriate to teach different aspects of prosthetics in isolation.'

Dental school 8 (south): 'We don't have it right by any means but we do try and integrate prosthetics including complete dentures with the rest of the school teaching and learning strategy. I appreciate that you are wishing to look at complete denture teaching in your questionnaire. My own feeling is that the skills are integrated rather than keeping complete dentures as a separate entity. Simple numbers do not tell the story of how we apply our teaching and learning strategy within the school.'

\section{DISCUSSION}

There was great disparity between schools in the overall number of lectures; two schools claimed 28 hours and the remainder varied between 6-15 hours. Four schools devoted more time to laboratory work whereas three schools spent more time in the clinic. One school reported no dedicated clinical time for complete dentures. There appears to be a regional variation with the northern dental schools spending more time on the teaching of complete dentures. The quota for complete dentures varied from three in most schools to eight in one school and none in another. Comments from the dental schools varied from a reported lack of suitable complete denture cases, to concerns with insufficient curricular time devoted to the subject and a subsequent lack of clinical competence on graduation. Some schools have integrated complete denture teaching into the general prosthodontic course as it is considered inappropriate to teach different aspects of prosthetics in isolation.

There is growing evidence to support a rethink on the way forward in complete denture teaching/training. In the USA there has been a "call to go back to basics"12 and an emphasis on the importance of teaching complete dentures with dental implants. Indeed, all restorative dentistry requires knowledge and understanding of the concepts of traditional complete denture construction. ${ }^{12,13}$

Despite the reduction in the trend to edentulism there will be an increase in the life span of the population to outweigh this reduction. ${ }^{14}$ There will always be a need for the construction of full dentures and that the continued physiological reduction of the alveolar ridge will make complete denture construction more difficult in the future. ${ }^{15}$

The dental school curriculum in the UK is governed by the standards set out by the General Dental Council. ${ }^{16}$ It provides a framework with which UK dental schools can structure their undergraduate curricula to ensure competency at a range of procedures including complete dentures. Competency is defined as: having a sound theoretical knowledge and understanding of the subject together with an adequate clinical experience to be able to resolve clinical problems encountered, independently or without assistance.

As evidenced by the preceding results, there are fundamental differences between the undergraduate schools as to how to ascertain whether their students had reached 'competency'. Some schools do not have 'requirements' but provide general guidelines as to what should be achieved. Others had numerical targets which themselves varied between individual schools. In 2007 a call was made to remedy the wide disparity between institutions. ${ }^{16}$

The British Society for the Study of Prosthetic Dentistry ${ }^{17}$ has questioned the level of competency, as defined by the GDC, being achieved by undergraduates, considering the amount of clinical and technical experience currently available on the undergraduate course. Dental foundation year 1 (DF1) training (formerly vocational training, VT) was intended to provide additional experience to the new graduate. However, with respect to removable prosthodontics it is anecdotally reported that this actually decreases during the DF1 year. This view is alluded to by the comment of dental school 3 (north): 'Students here gain an experience of complete denture prosthetics but it would be hard to say that the majority are competent in this subject when they qualify. Clinical experience is left for VT and this can be very patchy and dependent on the practice profile.'

\section{CLINICAL DENTAL TECHNICIANS}

The GDC adopted the suggestions of the Nuffield Foundation Report ${ }^{18}$ on education and training of personnel auxiliary to dentistry (1993) and have established the roles 
and responsibilities of non-dentists or dental care professionals (DCPs). Clinical dental technicians (CDTs) were registered by the GDC in July 2006, which gave them the right to practise as independent clinicians, rather than as part of a 'dental team'.

Wilson ${ }^{19}$ cited the lack of training, competency and regulation of CDTs for the deterioration in the provision of removable prosthodontic treatment for patients. These recent changes have adversely influenced the education of dental undergraduates.

Wilson ${ }^{19}$ had further noted that with the advent of CDTs, the dwindling time devoted to the teaching of complete dentures is of no concern since it would only be a matter of time before this topic is completely removed from the undergraduate curriculum. It was his wish to see CDTs trained alongside undergraduate dental students, but believed that there is no desire for this from the Heads of the undergraduate dental schools.

In a questionnaire study of 128 members of the Clinical Dental Technicians' Association, Ross et al. ${ }^{20}$ reported that a majority of the CDTs had obtained their education via George Brown College, Toronto, Canada. This course is $90 \%$ distance learning and the small clinical component is undertaken in Canada. The GDC document Developing the dental team ${ }^{21}$ and the GDC Scope of practice booklet ${ }^{22}$ stipulate that CDTs should already hold a recognised qualification in dental technology. As of March 2010, 127 CDTs were registered by the GDC (personal communication).

The influence CDTs will have in the future provision of complete dentures to the general population is in doubt.

'In this geographical area there are still significant numbers of edentulous patients who require care and therefore training in complete dentures is an important part of undergraduate education. There is still no realistic alternative to dentists providing care for patients as, to date, the registration of clinical dental technicians has had little impact in this geographical area and my suspicion is that this situation will not change for some time.' (dental school 12, north)

\section{CONCLUSION}

The results of the present investigation indicate that there are many differences in the UK undergraduate dental schools' philosophy towards complete dentures, from those stressing the continued importance of such teaching to those who wish to integrate it into other related topics. This supports the findings of $\mathrm{Clark}^{9}$ and Youngson. ${ }^{15}$

It would appear that the majority of undergraduate schools voice some doubts as to whether the current dental curriculum in complete dentures produces competency, as required by the GDC.

The dental school survey indicated that there were wide differences in the overall curriculum and that there is evidence of a north/south regional divide between the dental schools in the experience they offer their students. However, it should be noted that dental school 13 (north) did not consider the lack of time spent in teaching complete dentures was due to an unavailability of suitable patients. Generally the number of complete dentures required by undergraduate students to be made by the time of graduation is minimal.

Dental prosthetics had a dominant role in the dental curriculum of the first three-quarters of the twentieth century. Understandably, in the twenty-first century its influence has waned. The great reduction of caries in the population has not negated the need to train students how to deal with the disease; the same could be said for the treatment of the edentate population. There is a danger of a vicious circle being established with the lack of training and experience of the undergraduates affecting subsequent generations and thus the future recruitment of competent teachers with proficient skills and experience.

As a result of the findings from the undergraduate dental school teachers relating to the curriculum and level of competency in the provision of complete dentures, it was considered appropriate to seek the opinions of recently qualified dental practitioners. This is reported in the second paper of the series.

1. Feine J S, Carlsson G E, Awad M A et al. The McGill Consensus Statement on Overdentures. Montreal, Quebec, Canada. May 24-25, 2000. Int J Prosthodont 2002; 15: 413-414.

2. Thomason J M J, Feine J, Exley C et al. Mandibular two implant-supported overdentures as the first choice standard of care for edentulous patients - the York Consensus Statement. Br Dent J 2009; 207: 185-186

3. Douglass C W, Shih A, Ostry L. Will there be a need for complete dentures in the United States in 2020? J Prosthet Dent 2002; 87: 5-8.

4. Office of National Statistics. Adult Dental Health Survey: Oral Health in the United Kingdom 1998. Government Statistical service ONS; 99: 302.

5. Office of National Statistics. Adult Dental Health Survey - First release published 2010. Online information available at www.ic.nhs.uk/default. asp?sID=1300888592035 (accessed June 2013).

6. Alfano M C. Hedge our bet or trim our hedge: the need to reform the dental education process. Global Health Nexus, NYU College of Dentistry, Fall 2004. Online article available at www.nyu.edu/dental/ nexus/issues/fall2004/hedge.html (accessed June 2013).

7. McGarry T J. Guardians or luddites? Why are prosthodontics so resistant to change? J Prosthodont 2005; 14: 1-2.

8. McCord J F. Understanding prosthodontics where did it all go wrong? Int Dent J 2003; 53 (Suppl 5): 335-339.

9. Clark R K F, Radford D R, Juszczyk A S. Current trends in complete denture teaching in British dental schools. Br Dent J 2010; 208: 1-6.

10. Hancocks $S$. Beware the irony of the humble fullfull. Br Dent J 2010; 208: 327.

11. Dahlberg L, McCaig C (eds). Practical research and evaluation. Chapter 10. pp 147-158. London: Sage Publications Ltd, 2010.

12. Hawkinson R T. Letter to the Editor - A prosthodontic wake-up call: reaffirming the complete denture, implants alone do not solve the problems: the old principles are still important J Prosthodont 2005; 14: 294-295.

13. Faigenblum M J, Sharma P. Determining replacement teeth position for the implant-retained prosthesis in the edentulous patient. Alpha Omegan 2007; 100: 67-74.

14. Carlsson G E, Omar R. The future of complete dentures in oral rehabilitation. A critical review. J Oral Rehabil 2010; 37: 143-156.

15. Youngson C C, Molyneux L E, Fox K, Boyle E L, Preston A J. Undergraduate requirements in restorative dentistry in the UK and Ireland Br Dent J 2007; 203 (suppl): 9-14.

16. General Dental Council. The first five years. The undergraduate curriculum, 3rd ed (interim report). London: General Dental Council, 2008.

17. British Society for the Study of Prosthetic Dentistry (BSSPD) Newsletter (March 2006). Section 4 Undergraduate Training.

18. Nuffield Foundation Report 1993. Education and training of personnel auxiliary to dentistry. London: Nuffield Foundation, 1993.

19. Wilson J. The future for removable prosthodontics in the UK a personal opinion. Br Dent J 2007; 202: 653-654.

20. Ross M K, Ibbetson R J, Turner S. Activity and education of UK CDTs. Br Dent J 2007; 203: E22.

21. General Dental Council. Developing the dental team. London: General Dental Council, 2004.

22. General Dental Council. Scope of practice. London: General Dental Council, 2009. 